\title{
The student as a subject of transformative activity in the period of professional training
}

\author{
Tatyana Scherbakova ${ }^{1,{ }^{*}, \text { Dinamutdin } \text { Misirov }^{2}, \text { Marina Akopyan }}{ }^{2}$ and Larisa Ogannisyan ${ }^{2}$ \\ ${ }^{1}$ Don State Technical University, 1, Gagarina Square, 344003, Rostov-on-Don, Russia \\ ${ }^{2}$ Southern Federal University, 116, Dneprovskiy street, 344065, Rostov-on-Don, Russia
}

\begin{abstract}
The work includes a detailed analysis of the specifics of the current activity and description of its role in the development of professional success of future specialists in the context of modern sociorealism. Based on the results of the analysis of modern requirements to the student as a subject of autopsychological activity, the psychological factors of its productivity are identified. The paper presents a review of significant personal qualities of students, considered as internal determinants of successful transforming activity of a modern specialist: features of the value-semantic sphere, psychological, emotional and volitional characteristics of subjectivity. Factors that facilitate and block constructive activity aimed at promising transformations are shown. Considered extraction and interactively transformative in nature, their meaning and function in the development of the individual student. Various vectors of transformative activity in childhood are considered. The role of self-attitude, self-awareness, reflection of students' experience and knowledge in ensuring the productivity of their professional and personal growth is revealed. Based on the analysis of the results of an empirical study, we describe the content features of modern students' ideas about the essence and determinants of the positive transformative activity of its role in achieving future professional success.
\end{abstract}

\section{Introduction}

In modern psychological science, the problem of phenomenology and operationalization of multi-level determination of the transforming activity of the subject during the period of professional training at the University, the criteria for its productivity and development vectors in the context of the future life path is updated.

Today, there is also a question of strengthening the psychological component of training specialists in the field of not only humanitarian, but also technical areas of training. The risks and entropy of sociorealism set the task of expanding the individual psychological resources of future specialists in terms of increasing tolerance to uncertainty and the ability to preadapt [1-15]. The current conditions of psychological realization of professional activity require a specialist to be more creative in thinking, dynamic and mobile attitudes, psychoemotional stability, tolerance to stress and frustration, ability to subject analysis and

\footnotetext{
*Corresponding author: tatiananik@list.ru
} 
improvisation, flexibility and mobility of behavioral models, ability to set and successfully solve different levels of "tasks for meaning", decisiveness in decision-making, productive semantic and educational strategies [4]

In psychology today, the study of the possibilities of external and internal transforming activity of a person takes one of the priority places.

Psychological research demonstrates quite convincingly the importance of self-efficacy, effective functioning and constructive transformations of the subject, the ability to realize their abilities, reflection of individual resources, the ability to model behavior and activities, to productively cope with specific entropic situations of modern sociorealism, to constructively and creatively resolve contradictions and conflicts in order to achieve the success of the individual in various spheres of life $[5,6]$.

The multilayered problem situations of the modern socio-cultural situation of the development of a modern young person require special attention to the use of their resources as a subject of successful adaptation. In this regard, the issues of studying psychological neoplasms that provide high adaptability and personal negentropy in the entropy environment are being updated, which allows for successful development and effective interaction in the social space, showing psychological security [14]. As shown by the results of research by psychologists, an important role in the successful adaptation of the future specialist to the psychological and pedagogical conditions of professional training at the University is played by the existing level of social competence and the harmonization of the individual system of subjective control. The importance of studying the problem of the role of social competence and subjective control as the basic psychological determinants of constructive adaptation and productive functioning of the individual in the modern multicultural environment, factors that contribute to cultural security, increases due to the need to form and develop a culture of human security.

Social competence and subjective control play a special role in the development of adaptive capabilities of a student's personality and in the formation of a culture of security. it performs selective, regulatory, and regulatory functions in terms of managing their social activity in the multicultural environment of the University. In the modern multicultural educational space of the University, a student acts in real situations of interaction: with others, which are characterized by high dynamics, the presence of certain challenges and risks, in this context, the implementation of an individual system of subjective control depends largely on the level of development of social competence and ways of resolving emerging conflict situations [6].

The ability to analyze multicultural social conditions, identify information-rich markers, and predict the effects of specific actions increases the likelihood of a student's constructive adaptation. Here, it is important to form constructive personality styles: cognitive, emotional, communication and activity styles, and, finally, lifestyle [7].

The system of subjective control of social behavior and other types of activity involves emotions and feelings that arise in the student in relation to others. Emotions can act as internal barriers or initiate the beginning of certain actions. Emotional and evaluative attitude to others and oneself is an important component of the student's adaptation process [8].

Social competence reflects the degree of constructiveness of the student as a subject of interaction in the multicultural educational space of the University, ensuring the adequacy and effectiveness of adaptation, achieving real goals in a special social context of the multicultural environment, modeling and implementation of optimal multi-level communication [11].

This type of competence allows the student to analyze problem situations of interaction; find various alternative solutions; choose the optimal strategy of behavior, predicting the results of their actions. 
The student community of transformative activity can be divided into two types: extraction and interactively. The first type is manifested in different directions: through participation in: research projects, volunteer centers, volunteer movements, educational and professional competitions.

This allows you to create a psychological readiness to perform complex tasks of implementing nanotechnologies, robotics, functioning in the information space, and overcoming emerging risks. The second type is carried out through autopsychological activities aimed at self-creation, self-development, self-actualization and self-affirmation.

According to psychologists, the actualization of the ability to model behavior comes from the development of transformative activity, using past experience of success in achieving the goal; the belief in the need for personal growth, understanding the principles of building this type of activity: "awareness"," di-station", "inclusion"," constructive initiative", "modeling"," authorship", "responsibility" [13].

Ideas of future specialists about transformative activity affect the level of achievements, real behavior, as well as the development of the profession, reaching the maximum level of potential use and individual resources in professional training and life activity.

At the heart of transformative activity is a person's desire to grow, to expand abilities and strengthen resources and opportunities, to greater efficiency, personal maturity and psychological constructiveness $[15,16]$.

The meanings and values of the individual play an important role in actualizing the motivation of transformative activity [1].

Among the psychological components of determining successful transformation activity, psychologists identify adequate self-esteem, the level of claims; subjective control, confidence in oneself and the World, positive self-attitude and developed self-awareness, motivation for achievements, the ability to assert themselves, and value orientations.

The transformative activity reflects the desire for optimal development of resources, independence, ability to social modeling, self-criticism, and psychological readiness to take responsibility for their own lives.

The value-semantic sphere of the student is closely related to the success of the transformative activity and has a direct impact on the evaluation of the result.

One can distinguish new formations of the student period: perspective selfdevelopment, oriented to future goals, formation of a subjective personal position, establishment of clear external and internal psychological boundaries, personal perspective projects in different spheres of life, formation of life and professional plans, personalization in various aspects of life, integration of various levels of subjective control, formation of an individual system, positioning of oneself as a subject of one's own life, formation of selfdetermination of personal and professional growth $[2,11]$.

\section{Purpose of Investigation}

The aim of the study was to study students ' ideas about determinants and the peculiarity of transformative activity. The study assumed that students' subjective perceptions play an important role in determining transformative activity.

\section{Methods of Investigation}

The following methods were used as diagnostic tools: the author's questionnaire: "I am the subject of transformations" and the projective mini essay "Transformations". The study involved students of the southern Federal and don state technical universities of various training profiles in the number of 126 respondents. 


\section{Results and discussion}

The analysis of the study showed that students believe that transformative activity is important in the following positions: $28 \%$ - "expands the horizons of the individual"; 11 \%- "fashionable, modern"; $26 \%$ - "demand for time"; $15 \%$ - "obeying by others".

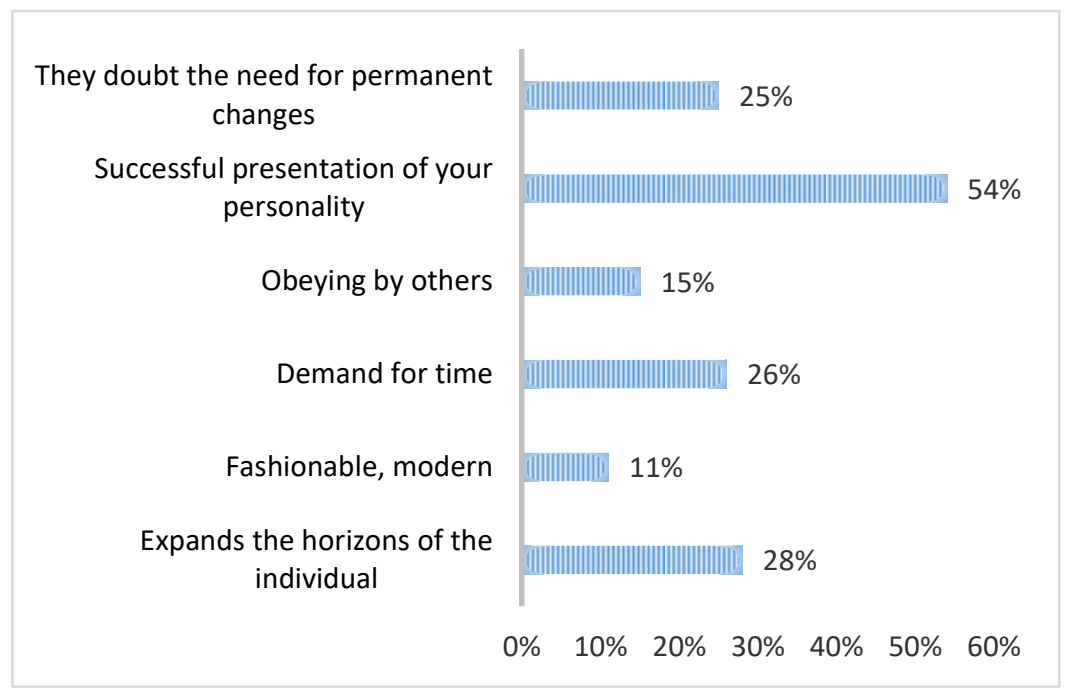

Fig. 1. Students ' understanding of transformative activity.

Many student respondents participating in the study demonstrate an understanding of the importance of mastering the activity that transforms the character.

The data obtained suggest that modern students treat pre-forming activity of the external and internal order as an individual way of self-realization, the possibility of self-realization and personalization. The study revealed that students believe that activity aimed at structural transformation affects "the formation of life plans and individual style". Students evaluate University education as a period when a person values transformation that are subjectively evaluated as progressive and accepts self-improvement as a necessary characteristic of modern youth. This period of lifetime is defined as a stage dedicated to self-determination, modeling of a personal project, strategy of one's life and creation of a personal image, building the boundaries of one's living space.

The importance of positive transformations for the successful representation of their identity in the professional community and society is noted by $54 \%, 25 \%$ - doubt the need for permanent changes.

As a result of summarizing the answers, it can be argued that in the representation of students who participate in the study, transformative activity performs the following functions: providing professional and personal growth, adaptation, design, stimulation, and manifestation of individuality.

Students' ideas about the factors that encourage a person to perform transformative activity are quite interesting:

The desire to improve the quality of life, openness to new things, the desire for change, the thirst for success, the demands of others, the values of the family or modern society. Analysis of survey results and texts of students ' projective mini-essays made it possible to identify and systematize factors that facilitate and block constructive activity aimed at promising transformations. The cluster of facilitators includes the following: stimulating characteristics of the University environment; examples of significant others; family 
traditions; heroic images and works of art; asserting infinite possibilities for development; motivation of achievements, motives of growth and competence; competitiveness of educational, professional and social environment; availability of perspective life plans and personal position; desire to get recognition; desire to test individual opportunities, developed will. The group of blocking factors included such as: laziness; lack of meaning; negative plumes of past experience; lack of support for others; lack of time; incomplete self-determination; insufficient level of development of autopsychological competence; low motivation; environmental standards; lack of understanding of the advantages of continuous self-development; psychological complexes; negative non-constructive assessments from significant others. Highlighting interactively transform-present nature, respondents indicate their meaning and function in the development of the human personality. Hyperactivity involves the transformation of the environment, primarily through research and project activities and actions of a voluntary and volunteer nature. this also includes social modeling to create a supportive micro-social environment, a team. Transformative Hyperactivity allows you to develop social and communicative competence, gain experience in testing and implementing results of research projects, and work in a team. With regard to interactivity, attention is focused on the consciousness of transformations in the cognitive and emotional-volitional spheres, self-education of character traits that are defined as valuable for the student's personality, the importance of developing competence, competitiveness, and acquiring skills to optimally use their individual potential. Showing this type of activity, the student gets the opportunity to test their autopsychological skills, to show subjective characteristics, to show perseverance and purposefulness, to test various models of self-presentation, to increase the level of self-esteem.

In the course of the survey, psychological barriers that make it difficult for students to make positive transformations are highlighted. These include the following barriers: environmental, informational, personal, value-semantic, reflective, cognitive, emotional, and motivational.

Psychological barriers, according to students, arise in the process of interaction with the environment and as a result of insufficient knowledge of their capabilities and individual characteristics. Respondents identify various vectors of transformative activity in the student age: social actions to improve the environment, environmental and historical projects, organization of volunteer movements that increase social activity of young people, formation of a healthy lifestyle, participation in creative associations, target focus groups and creative teams, creation of positively oriented forms of student subculture. In terms of increasing autopsychological activity, the following vectors are highlighted: deepening selfknowledge, forming a stable positive Self-concept, developing motives for growth and subjectivity, and accumulating experience in self-transforming activities. Students recognize the significant role of self-attitude, self-awareness, reflection of students' experience and knowledge in ensuring the productivity of their professional and personal growth. Based on the analysis of the results of an empirical study, the author describes the content of modern students ' ideas about the essence and determinants of positive transformative activity and its role in achieving future professional success. The factors that determine the success of a student as a subject of transformations are highlighted.

As shown by the analysis of the set of data identified as a result of the study, typical representations that characterize the understanding of modern students, the content of external and internal transformative activity, and its functions are highlighted. Among the attitudes underlying the willingness to be a subject of continuous self-development and transform the environment, students list the following: self-realization, progress, creation, life-creation, identity.

The importance of the results obtained in the study for improving the system of professional training of a specialist in higher education is determined, first of all, by the fact 
that the content features of individual students ' ideas about the specifics of transformative activity are the material for predicting the future individual trajectory of professional and personal growth and forming their own life project.

Subject analysis of empirical data shows that most students believe that external and internal transformations today are components of the portrait of a modern successful person, approved lifestyle, a kind of business card of the subject.

It is interesting that many students believe that the implementation of the activity of transformation helps to increase self-esteem and self-confidence, acceptance and successful self-presentation.

Among the personal characteristics that influence the choice of constructive models of transformative activity, students stand out: purposefulness, competence, motivation, the desire to live interestingly, the desire to experiment, attitude, modernity, courage, optimism.

Thus, at the student age, ideas about the possibility of transformative activity in choosing a life strategy and lifeline, as well as about the professional perspective and perspective vectors of self-development in modern sociorealism are determined. Productive autopsychological transformative activity during the student period involves finding the optimal correlation of one's personal potential and individuality with the chosen profession. The most important condition for successful self-transformation is the expansion of General and professional knowledge, and the availability of reflexed experience; the presence of a development-supporting environment and modern training programs for autopsychological activities.

\section{References}

1. I.V. Abakumova, General theory of meaning, psychological concepts of meaning formation, meaning didactics (Ed. "Credo", Moscow, 2013)

2. K.A. Abulkhanova-Slavskaya, Personality Time and lifetime (Aleteia, Saint Petersburg, 2001)

3. A.G. Asmolov, Optics of Enlightenment: Sociocultural (Enlightenment, Moscow, 2015)

4. S.V. Gurov, Features of semantic strategies in students of different professional orientation, Diss. Cand. (The Southern federal University, Rostov-on-don, 2012)

5. E.F. Zeer, Personal-developing professional education-Catherine-Burg (Publishing house of the state University of higher education Russian state Prof.-PED. University, 2006)

6. I.B. Kotova, Proceedings of the Southern Federal University. Pedagogical science 5, 65 $-72(2013)$

7. D.A. Leontieva, Personal potential: structure and diagnostics (Smysl, Moscow, 2011)

8. E.V. Matukhnom, Scientific notes of the Komsomol-on-Amur state Technical University 2(3), 50 - 53 (2010)

9. D. N. Misirov, Proceedings of the Southern Federal University. Pedagogical Sciences: scientific and pedagogical journal (Publishing house of the southern Federal University, Rostov-on-Don, 2011)

10. S.A. Penyaeva, Higher education in Russia 4, 31-34 (2007)

11. E.V. Roschevskaya, Izvestia of the southern Federal University. Pedagogical science 9, 109-116 (2013)

12. E.P. Romanenko, Izvestia of the southern Federal University. Pedagogical science 10, 93-103 (2017) 
13. T.N. Shcherbakova, The success of a teacher in a multicultural educational environment: diagnostics, development technologies (Publishing house of the state University of RPK and PPRO, Rostov-on-don, 2019)

14. T. Shcherbakova, I. Loseva, D. Misirov, I. Zhitnaya, Scientific almanac of the black sea Region countries 2(18), 25-33 (2019) DOI 10.23947/2414-1143-2019-18-2-25-33

15. R.M. Ryan, E.L. Deci, Self-determination theory: Basic psychological needs in motivation, development, and wellness (Guilford Publishing, New York, 2017)

16. J.C. Norcross, P.M. Krebs, J.O. Prochaska, Journal of Clinical Psychology 67(2), $143-154(2011)$ 